\title{
Vagus nerve stimulation affects pain perception in depressed adults
}

\author{
Jeffrey J Borckardt PhD ${ }^{1,2}$, F Andrew Kozel MD MS 1,3,4, Berry Anderson RN ${ }^{1}$, \\ Angela Walker LPN ${ }^{1}$, Mark S George MD ${ }^{1,3,4}$
}

\begin{abstract}
JJ Borckardt, FA Kozel, B Anderson, A Walker, MS George. Vagus nerve stimulation affects pain perception in depressed adults. Pain Res Manage 2005;10(1):9-14.
\end{abstract}

BACKGROUND: Previous research suggests that vagus nerve stimulation (VNS) affects pain perception in epilepsy patients, with acute VNS decreasing pain thresholds and chronic VNS treatment increasing pain thresholds. However, no studies have investigated the effects of VNS on pain perception in chronically depressed adults, nor have controlled, systematic investigations been published on the differential effects of certain VNS device parameters on pain perception.

OBJECTIVES: The present study tried to replicate the results of previous research showing acute pronociceptive effects of VNS and determine the effects of various device parameter settings on pain tolerance. The present study also investigated the relationship among patients' levels of depression, duration of VNS treatment and VNSinduced changes in pain perception.

METHODS: A thermal pain challenge task was used to determine pain tolerance during VNS device activation using different combinations of VNS device parameter settings within subjects undergoing VNS therapy for chronic depression.

RESULTS: Significant pronociceptive effects were found for acute VNS activation. Individual differences were found with respect to the VNS settings associated with the largest changes in pain perception. Severity of depression was inversely related to baseline pain tolerance, but depression severity was unrelated to VNS-induced acute changes in pain tolerance, as was the length of time participants had been undergoing VNS treatment.

CONCLUSIONS: VNS appears to affect pain perception in depressed adults. Different VNS parameter settings may be associated with unique effects from patient to patient. More studies are needed to determine the long-term effects of VNS on pain perception.

Key Words: Depression; Device parameters; Pain; Vagus nerve stimulation

\section{La stimulation du nerf vague modifie la per- ception de la douleur chez les adultes déprimés}

\begin{abstract}
CONTEXTE : Selon des recherches antérieures, la stimulation du nerf vague $(\mathrm{SNV})$ modifierait la perception de la douleur chez les patients épileptiques : la stimulation brève abaisserait les seuils nociceptifs, tandis que la stimulation prolongée les élèverait. Cependant, aucune étude n'a porté sur les effets de la SNV sur la perception de la douleur chez des adultes en état de dépression chronique, pas plus que des travaux de recherche systématique, comparative n'ont été publiés sur les différences d'effets de certains paramètres des appareils de SNV sur la perception de la douleur.
\end{abstract}

BUTS : La présente étude avait pour buts de reproduire les résultats d'une recherche antérieure montrant les effets pronociceptifs aigus de la SNV et de déterminer les effets de divers paramètres sur la tolérance à la douleur. L'étude a aussi porté sur les liens entre le degré de dépression des patients, la durée du traitement par la SNV et les variations de perception de la douleur liées à la SNV.

MÉTHODE : Pour ce faire, nous avons eu recours à une tâche douloureuse d'origine thermique pour déterminer la tolérance à la douleur durant la SNV en associant différents paramètres chez des sujets traités par la SNV pour une dépression chronique.

RÉSULTATS : Nous avons noté des effets pronociceptifs marqués pendant la stimulation brève du nerf vague. Des différences individuelles ont été observées en ce qui concerne les paramètres de la SNV associés aux écarts les plus importants de perception de la douleur. Le degré de gravité de la dépression s'est montré inversement proportionnel au seuil de tolérance à la douleur au départ, mais aucun lien n'a été établi entre le degré de gravité de la dépression et les variations marquées de la tolérance à la douleur provoquées par la SNV, tout comme la durée du traitement par la SNV.

CONCLUSIONS : La SNV semble modifier la perception de la douleur chez les adultes déprimés. Le réglage des différents paramètres de la SNV pourrait être associé à des effets propres à chaque patient. Il faudrait mener d'autres études pour déterminer les effets à long terme de la SNV sur la perception de la douleur.
Vagus nerve stimulation (VNS) in humans involves surgical implantation of an electronic stimulator in a patient's chest. An electrode is threaded subcutaneously and attached to the vagus nerve in the neck. The stimulator provides electrical stimuli to the brain that can be controlled by a clinician or researcher (with respect to the output current, frequency, pulse width and stimulation on/off cycle). VNS was first investigated in humans and approved as a treatment for epilepsy (1-5).
It continues to be a widespread and growing treatment option for epilepsy $(6,7)$.

VNS has also been investigated as an antidepressant. Initial open label studies found VNS to have acute antidepressant effects, and at the one-year follow-up, response rates were sustained while remission rates increased $(8,9)$. However, a recent multisite, double-blind study failed to find statistically significant, acute antidepressant effects between VNS and sham treatment (10).

${ }^{1}$ Brain Stimulation Laboratory, Department of Psychiatry; ${ }^{2}$ Counseling and Psychological Services; and ${ }^{3}$ Center for Advanced Imaging Research, Medical University of South Carolina; ${ }^{4}$ Ralph H Johnson VA Medical Center, Charleston, South Carolina

Correspondence and reprints: Dr Jeffrey J Borckardt, Institute of Psychiatry, 67 President Street, PO Box 250861, Medical University of South

Carolina, Charleston, South Carolina 29425, USA. Telephone 843-792-3295, fax 843-792-2535, e-mail borckard@musc.edu 


\begin{tabular}{|c|c|c|c|c|}
\hline Subject & $\begin{array}{l}\text { Output current } \\
\text { (ma) }\end{array}$ & $\begin{array}{c}\text { Frequency } \\
(\mathrm{Hz})\end{array}$ & $\begin{array}{l}\text { Pulse width } \\
(\mu \mathrm{s})\end{array}$ & $\begin{array}{l}\text { Duty cycle } \\
\text { (on/off) (s) }\end{array}$ \\
\hline 1 & 1.25 & 20 & 500 & $30 / 180$ \\
\hline 2 & 0.50 & 20 & 250 & $30 / 180$ \\
\hline 3 & 2.75 & 20 & 250 & $30 / 180$ \\
\hline 4 & 1.50 & 20 & 130 & $30 / 180$ \\
\hline 5 & 0.50 & 15 & 130 & $30 / 300$ \\
\hline 6 & 0.50 & 15 & 250 & $30 / 180$ \\
\hline 7 & 0.75 & 20 & 250 & $30 / 600$ \\
\hline 8 & 0.75 & 20 & 250 & $30 / 180$ \\
\hline
\end{tabular}

There is some evidence that VNS affects pain perception (11-14). Although numerous medical and psychosocial interventions are available to treat chronic pain, many sufferers report that they do not experience significant or even appreciable relief from currently available treatments $(15,16)$; therefore, investigation of new interventions with the potential to treat pain is warranted.

Several studies have demonstrated that VNS alters pain perception in rats, cats and monkeys (17-20). Findings suggest that, in general, low-intensity VNS is associated with pronociceptive effects, but high-intensity VNS is associated with antinociceptive effects.

Kirchner et al (13) examined the effects of VNS on pain perception in 10 epilepsy patients (pre- and postdevice implantation) and 12 age-matched healthy volunteers (no device implantation). Wind-up pain was significantly reduced in the VNS group pre-to-post implant, and antinociceptive VNS effects were found for tonic-pressure pain pre-to-post device implant. With regard to thermal pain, a trend was found indicating an increase in pain threshold over time (measurements were taken at preimplant, two to five days postimplant, and eight to 14 weeks postimplant) within the VNS group, but no difference was found between the VNS and control groups (possibly because of small effect sizes and limited sample size).

Kirchner et al (13) also provided an anecdotal report about one patient with chronic tension-type headaches for more than 10 years. An 80\% reduction of headache was reported after implantation of the VNS device. As with many case reports, it is difficult to determine whether the VNS was causal in these clinical improvements.

Ness et al (13) found that acute thermal pain thresholds were lower during VNS activation than while the device was off (acutely pronociceptive). However, VNS frequency and pulse width settings were not modified in this study.

These studies suggest that, at the very least, VNS interacts with (and perhaps alters) neural circuits involved in pain perception, although it is not entirely clear how VNS impacts pain perception in humans. It is currently unknown whether VNS affects pain perception in humans through the modulation of thalamic activity, somatosensory cortex activity or limbic structure activity; through activating structures involved in the cognitive appraisal of pain; or through some other mechanism. More data are needed to determine the reliability of the findings that VNS affects pain experience and to ultimately help articulate the mechanisms of action.
Recent imaging research has shown that different VNS parameters (frequency [21], intensity [22], pulse width $[23,24])$ result in activation of different regions of the brain. Therefore, it is important to investigate the effects of different parameter settings to better understand how VNS works and, potentially, how to optimize treatment for specific neuropsychiatric conditions.

The two previous studies of VNS and pain perception in humans were conducted on patients with seizure disorders. Currently, no studies have been published regarding the effects of VNS on pain perception among patients without epilepsy. Chronically depressed patients make up an important group to study because the comorbidity of chronic pain and depression is quite high $(15,24,25)$.

The present study sought to develop a better understanding of the effects of VNS device activation on acute pain perception among a convenience sample of adults receiving VNS for the treatment of depression. Specifically, the present study tried to determine whether different VNS device parameter settings were associated with acute changes in pain perception, and if so, which ones. Additionally, the present study aimed to determine whether a relationship exists between depression and acute VNS-induced changes in pain perception.

\section{METHODS}

\section{Participants}

The participants were eight volunteers (two men, six women) from the roster of VNS patients enrolled in the studies investigating VNS as a treatment for depression at the Brain Stimulation Laboratory (BSL) at the Medical University of South Carolina (MUSC). The mean age of the sample was 48.6 and all eight participants were Caucasian. On the day of the testing, the average length of time participants had been receiving VNS therapy for depression was 35.33 months $(\mathrm{SD}=7.76$ months, minimum $=24$ months, maximum $=48$ months). The mean Hamilton Depression Rating Scale (HDRS) score of the sample on the day of participation was $22.13(\mathrm{SD}=10.41)$, indicating that on average, the participants were depressed at the time of participation (common depression cut-off scores on the HDRS are 10 to 12). Participants were paid $\$ 30.00$ each for participating. At the time of the study, the chronic active VNS device settings varied depending on the clinical decisions made by each participant's treating physician throughout the course of VNS treatment. Table 1 lists the chronic VNS device settings of the eight participants in the present study. In addition to receiving VNS, participants were taking antidepressant medications at the time of the study. However, medications had not been changed in the three months before participation.

\section{VNS device settings}

The participants' VNS devices were tested and the baseline (chronic) device settings were recorded. During the experiment, one of the researchers (FAK) reprogrammed VNS device settings with a laptop computer. Twelve different VNS device settings and six control settings (ie, zero current or sham VNS) were investigated. The device settings investigated were a randomized ordering of the following $(3 \times 2 \times 3)$ parameter options:

- Output current: $0 \%, 50 \%$ or $100 \%$ of the participants' initial baseline chronic device setting;

- Frequency: $20 \mathrm{~Hz}$ or $30 \mathrm{~Hz}$; and

- Pulse width: $130 \mu$ s, $250 \mu$ s, or $500 \mu$ s. 
Each condition with a current of $0 \%$ was a control condition (sham VNS). If a device was incapable of producing an output current of exactly $50 \%$ of the initial device settings, the closest output current was used for the $50 \%$ output trials. Table 2 contains a sample block of randomized VNS device settings. Participants and the investigator interacting with the participants (JJB) were blinded to all device settings. After the research session was completed, the participants' VNS devices were set back to the original chronic baseline settings and they were sent home. The entire session lasted approximately $90 \mathrm{~min}$, not including the clinical depression assessments.

Some settings were not tolerated well by all participants. For one participant, output current/frequency/pulse width settings of $100 \% / 30 \mathrm{~Hz} / 500 \mu$ s and $100 \% / 20 \mathrm{~Hz} / 500 \mu$ s produced significant coughing and these settings were discontinued after completing one heating trial. For another participant, $100 \% / 30 \mathrm{~Hz} / 500 \mu$ s produced significant cough and it was discontinued after one trial. Additionally, to avoid producing further discomfort, $100 \% / 30 \mathrm{~Hz} / 250 \mu \mathrm{s}$ and $100 \% / 30 \mathrm{~Hz} / 130$ us were not used with this participant. For the within-subject analyses, the missing-value functions of Statistical Package for the Social Sciences (SPSS 11, SPSS Inc, USA) provided the values for the missing cells so that the patient's results could be used for the analyses. In addition to the missing data described above, some data points were disregarded before importing the data into the statistical package due to one or more of the following reasons:

- the participant was experiencing discomfort or cough from the VNS setting and could not focus on a particular heating trial;

- the participant failed to place his/her finger on the heating surface properly, resulting in a failure to transmit heat to his/her finger; and/or

- the participant failed to place his/her finger on the heating surface properly, disrupting the thermocouple and resulting in erroneous temperature readings.

Of the expected 608 data points ( 19 setting conditions $[3 \times 2 \times 3$ +1 baseline period] $\times 4$ trials each $\times 8$ participants $=608), 540$ data points were recorded and imported to SPSS 11 (11\% missing). Post hoc analysis revealed that the missing data points were uniformly distributed across the setting conditions (one-sample Kolmogorov-Smirnov test for deviation from a uniform distribution $\mathrm{Z}=1.07, \mathrm{P}=0.20$ ), and the number of available data points for each of the specific settings were not significantly affected by the missing data.

\section{Method for producing mild thermal pain}

A $5 \mathrm{~cm}^{2}$ portion of a ceramic tile $(1 \mathrm{~cm}$ thick) was heated by an Omega SRMU 3-inch Round Silicon Heater (Omega Engineering Inc, USA). The heater and tile were placed on top of a wooden box that sat on a desk in front of the participant. A self-adhesive $900 \mathrm{~mm}$ Teflon-insulated Thermocouple (Omega Engineering Inc, USA) was attached to the tile and fed into an Omega CN9600 Series Digital Autotune Temperature/Process Controller (Omega Engineering Inc, USA), which in turn controlled the silicon heater. The digital controller was used to continuously monitor and control the temperature of the tile to exactly $52^{\circ} \mathrm{C}$. During each heating trial, the participant placed the digiti minimi of his/her left hand on the portion of the tile that was in contact with the heater and near the attached thermocouple. The participant was instructed to remove his/her finger from the tile at the point he/she determined
TABLE 2

\begin{tabular}{lcccc}
$\begin{array}{l}\text { Sample block of random device settings showing } \\
\text { interspersed control conditions* }\end{array}$ \\
\hline Trial & Output (\%) & Frequency (Hz) & Pulse width ( $\boldsymbol{\mu s})$ & Device \\
\hline 1 & 0 & 20 & 500 & OFF \\
2 & 100 & 30 & 250 & ON \\
3 & 50 & 20 & 250 & ON \\
4 & 50 & 30 & 130 & ON \\
5 & 100 & 20 & 130 & ON \\
6 & 0 & 20 & 250 & OFF \\
7 & 100 & 30 & 130 & ON \\
8 & 0 & 30 & 500 & OFF \\
9 & 50 & 20 & 130 & ON \\
10 & 0 & 30 & 130 & OFF \\
11 & 100 & 20 & 500 & ON \\
12 & 100 & 30 & 500 & ON \\
13 & 0 & 20 & 130 & OFF \\
14 & 50 & 20 & 500 & ON \\
15 & 0 & 30 & 250 & OFF \\
16 & 50 & 30 & 250 & ON \\
17 & 100 & 20 & 250 & ON \\
18 & 50 & 30 & 500 & ON \\
\hline
\end{tabular}

${ }^{*}$ Actual blocks were different for each subject

it to be 'uncomfortably hot'. A custom-developed computer program recorded the amount of time (in milliseconds) the participant was able to keep his/her finger on the hot tile. This information was silently recorded by the program and saved to a data file.

\section{Depression ratings}

Each participant's depression level was assessed by a trained psychiatric nurse in the BSL at MUSC. For each participant, the HDRS was completed approximately $30 \mathrm{~min}$ before participation in the present study. The researchers were not told the HDRS scores until after completion of the pain experiment.

\section{Procedures}

The participants were brought individually to a quiet office in the BSL at the MUSC. One of the researchers carefully reviewed the informed consent form with each patient and both the researcher and the participant signed the form. The participants were interviewed briefly about any reported history of chronic pain conditions. Their VNS devices were interrogated and the initial settings were recorded. The heating and computer measurement procedures were explained and demonstrated. Participants were given a chance to practice the heating procedures for a minimum of five times or until they were comfortable with the tasks before beginning the experiment.

Once participants had demonstrated a mastery of the procedures, their VNS devices were turned off and four baseline trials were conducted. Each participant was assigned a unique randomized list of device settings (consisting of 18 setting combinations including six interspersed sham VNS settings). One of the researchers (FAK) programmed the participant's VNS device with a setting from the list. Both the participants and the researcher (JJB) interacting with the participants were blinded to the settings being used.

The participants completed four trials for each VNS setting. The VNS devices were programmed to be 'on' for the first $60 \mathrm{~s}$ of 


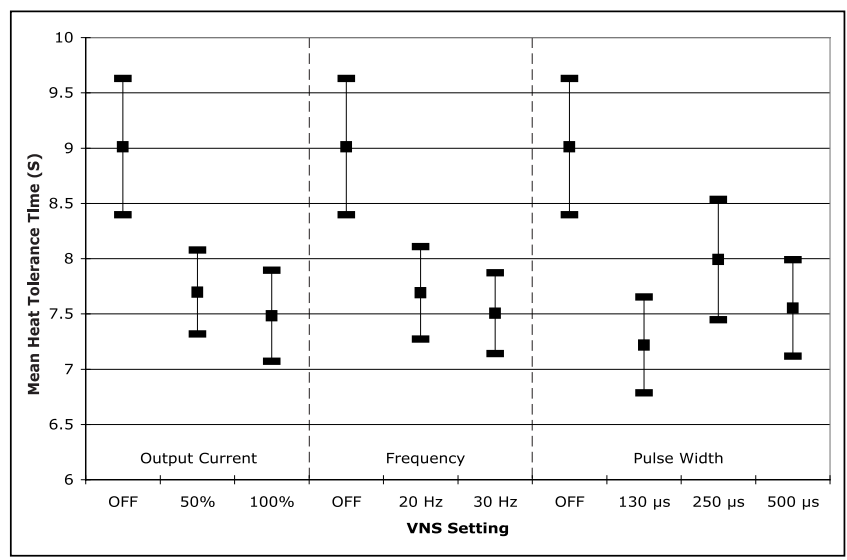

Figure 1) Mean heat tolerance time (and 95\% CIs) in seconds of eight depressed vagus nerve stimulation (VNS) patients across each level of each VNS device parameter investigated (main effects)

each block of four trials. The computer program was designed to pace the trials such that a minimum of $25 \mathrm{~s}$ elapsed between each trial. Approximately 2 min were allotted between each setting condition (every four trials) to allow researchers to change device settings and to allow subjects to relax and prepare for the next four-trial setting condition.

\section{Statistical analysis}

Data were analyzed with the SPSS 11 for Mac OS X. Since the study employed a small sample size $(n=8)$, nonparametric procedures were used for within-subject statistical analysis.

\section{Assurance}

The present study was approved by the Institutional Review Board at MUSC, and all participants provided written informed consent before participation.

\section{RESULTS}

\section{Participant pain histories and anecdotal reports}

Seven of the participants (87.5\%) reported a history of chronic pain including headache, low back pain and neck pain. Two of these participants $(28.6 \%)$ reported noticing changes in pain experience after VNS implantation.

One participant reported that he injured his back 20 years before VNS implantation and that he experienced debilitating low back pain and daily tension-type headaches. He reported that since the VNS device implantation, he had one headache per month on average and that he was no longer "bothered" by back pain. Another participant reported that she injured her back in a car accident 10 years before her device implantation. She reported that she maintained functioning despite the pain but experienced less pain since device implantation.

\section{Effects within VNS blocks}

No significant differences were found in the length of time participants were able to tolerate the hot tile across the four trials in each active VNS setting block (Friedman $\chi^{2}[\mathrm{n}=8$, $\mathrm{df}=3]=3.30$, not significant). Therefore, heat tolerance times were collapsed across trials (four per VNS setting condition) and means for each VNS setting condition were used in withinsubject statistical analyses.

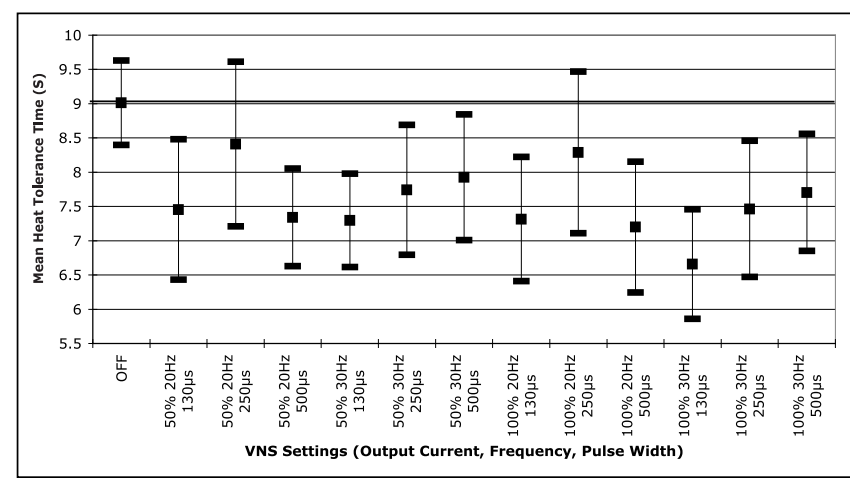

Figure 2) Mean heat tolerance time (and 95\% CIs) in seconds of eight depressed vagus nerve stimulation (VNS) patients for each individual combination of VNS device settings investigated

\section{VNS effects on heat tolerance duration}

The mean time participants were able to tolerate the hot tile across all conditions was $8.25 \mathrm{~s}(\mathrm{SD}=3.79 \mathrm{~s})$. An overall effect for VNS activation on heat tolerance times was found (Friedman $\left.\chi^{2}[\mathrm{n}=8, \mathrm{df}=17]=27.60, \mathrm{P}<0.05\right)$. Figure 1 shows the mean heat tolerance times (with $95 \%$ CIs) across the different VNS parameter settings (main effects).

Output currents of $50 \%$ and $100 \%$ of maximal current were associated with significant decreases in heat tolerance times compared with sham VNS (Wilcoxon Signed Ranks Test $Z=-2.38, P<0.025$ and $Z=-2.10, P<0.05$, respectively). However, there was no difference in heat tolerance times between the $50 \%$ and $100 \%$ output currents $(Z=-0.98$, not significant $)$.

Frequency settings of $20 \mathrm{~Hz}$ and $30 \mathrm{~Hz}$ were associated with significant decreases in heat tolerance times compared with sham VNS (Wilcoxon Signed Ranks Test $\mathrm{Z}=-2.38, \mathrm{P}<0.025$ and $\mathrm{Z}=-2.38, \mathrm{P}<0.025$, respectively). There was no difference in heat tolerance times between the $20 \mathrm{~Hz}$ and $30 \mathrm{~Hz}$ conditions $(Z=-0.70$, not significant).

A pulse width of $130 \mu$ s was associated with significant decreases in heat tolerance times compared with sham VNS $(\mathrm{Z}=-2.38, \mathrm{P}<0.025)$, as was a pulse width of $500 \mu \mathrm{s}(\mathrm{Z}=-2.10$, $\mathrm{P}<0.05)$. However, a pulse width of $250 \mu \mathrm{s}$ did not have a significant effect on heat tolerance ( $\mathrm{Z}=-1.82$, not significant). Additionally, heat tolerance time did not differ between $130 \mu$ s and $250 \mu \mathrm{s}(Z=-0.84$, not significant), $130 \mu \mathrm{s}$ and $500 \mu \mathrm{s}(\mathrm{Z}=-0.70$, not significant), or $250 \mu$ s and $500 \mu$ s ( $Z=-0.70$, not significant).

No significant interaction effects were detected; however, statistical power was low due to the small sample size. Figure 2 shows the mean heat tolerance times for all eight participants across all of the settings investigated. The following setting conditions were associated with the largest average changes in heat tolerance time: $100 \% / 30 \mathrm{~Hz} / 130 \mu \mathrm{s}, 100 \% / 20 \mathrm{~Hz} / 500 \mu s$, and $50 \% / 30 \mathrm{~Hz} / 130 \mu \mathrm{s}$. Each of these settings produced average changes in heat tolerance times that were greater than $0.5 \mathrm{SD}$.

Table 3 shows the single combination of settings associated with the largest changes in pain perception for each individual participant. Two participants experienced the largest change in pain tolerance with $50 \% / 30 \mathrm{~Hz} / 250 \mu$ s. Each of the other participants experienced the largest change in pain perception with a unique combination of settings.

Effects of depression and VNS duration on pain experience HDRS scores were significantly related to baseline pain tolerance (Spearman $r h o=-0.82, \mathrm{P}<0.025)$. Participants who were 
more depressed (with higher HDRS scores on the day of the study) had lower baseline pain tolerances (ie, they were more sensitive to pain). However, HDRS scores were not significantly related to VNS-induced changes in pain tolerance (mean heat time during VNS minus mean heat time during device-off conditions; Spearman $\mathrm{rho}=0.301$, not significant). The length of time that the participants had been receiving VNS therapy was also unrelated to changes in pain tolerance (Spearman $\mathrm{rho}=0.012$, not significant).

\section{DISCUSSION}

This study suggests that stimulation of the vagus nerve affects pain perception in medicated, depressed adults receiving chronic VNS therapy. The findings suggest an acute decrease in thermal pain tolerance during device activation. Thus, the results in patients with depression partially replicate and extend the findings of Ness et al (14). The present study was an acute challenge study and did not find any significant antinociceptive effects. It is important to note that antinociceptive VNS effects have only been found with longer-term VNS in humans (13) and higher intensity stimulation in animals $(17,18)$.

The present study suggests that various VNS parameters might be associated with differential effects on pain perception. Although statistical power is limited in this study, Figures 1 and 2 provide preliminary evidence that device parameter interactions may be present, and that certain device settings may be associated with larger acute changes in pain perception. Additionally, individual differences in pain perception alteration in response to various device settings may be worth investigating in future studies, as six (75\%) of our participants experienced the largest individual changes in pain perception with unique device settings. These individual differences may make it difficult to determine reliable predictors of VNS response with only eight participants, and it should be noted that, given the small sample size, these results are difficult to interpret.

The participants' levels of depression (and duration of VNS therapy) were unrelated to the VNS-induced changes in pain perception, although higher levels of depression were associated with lower baseline pain tolerance. There may not be enough power with only eight participants to detect a real relationship between depression and VNS-induced alterations in pain perception - if one does exist. Additionally, the response to VNS for depression may influence the response to VNS-induced changes in pain perception, although this question was not directly addressed in this preliminary study.

As mentioned above, a weakness of this study is the limited sample size, which may have limited the power to detect real effects and associations between variables and conditions. The sample is not representative in terms of size, sex, age or ethnicity, and therefore, the results should be interpreted with caution. Another limitation involves the methods used to produce mild thermal pain. The unconventional approach used in this study was chosen because of its cost-effectiveness as a pilot procedure to determine the feasibility of enrolling more participants and employing more sophisticated and reliable methods of inducing laboratory pain. Also, given the limitations of the exploratory design employed in this study, it is difficult to rule out the effects that differences in antidepressant medication may have had on pain perception and/or the relationship between depression and pain perception in our sample. The participants were taking antidepressant medications at the time of the study in addition to receiving VNS; however, medications

$\begin{aligned} & \text { TABLE } 3 \\
& \text { Vagus nerve stimulation device settings that produced the } \\
& \text { largest changes in thermal pain threshold for each } \\
& \text { individual subject }\end{aligned}$
\begin{tabular}{lccc}
\hline Subject & Output current (\%) & Frequency $(\mathrm{Hz})$ & Pulse width $(\boldsymbol{\mu s})$ \\
\hline 1 & 100 & 30 & 250 \\
2 & 50 & 30 & 250 \\
3 & 50 & 30 & 130 \\
4 & 50 & 30 & 250 \\
5 & 100 & 30 & 500 \\
6 & 50 & 30 & 500 \\
7 & 50 & 20 & 130 \\
8 & 50 & 20 & 250 \\
\hline
\end{tabular}

had not been changed in the three months before participation. Because this study focused on acute changes in pain tolerance in response to VNS device parameter changes (from minute to minute), and because changes in pain tolerance were examined within-subjects across time (ie, participants served as their own controls), differences in pain tolerance between-subjects (that might have been related to medication differences) have little impact on the interpretation of the data. However, it is difficult to rule out the potential impact of the various medications on the participants' pain-threshold reactivity to VNS, which is a serious limitation of this study.

Similar to the studies by Ness et al (14) and Kirchner et al (13), the VNS output currents investigated in the present study were selected from the large number of therapeutic settings used by treating physicians for clinical purposes. However, these settings might differ from the maximum tolerable settings in some cases, and given the individual differences found in this study, they may not be optimal settings for all patients. Future studies might determine the feasibility and utility of determining the maximum tolerable output setting for each participant to maximize effect sizes and to ensure that participants are receiving an adequate VNS 'dose'. In the present study, the participants that had difficulty tolerating all the levels of frequency and pulse widths investigated were those with the highest chronic output currents. Therefore, future studies should assess the maximum tolerable output current, not only to ensure adequate dose, but also to assure that the dose is not too high for the laboratory procedures.

Lastly, the present study lends preliminary support to the notion that VNS effects on pain perception might be used as an index of VNS activation and neural responsiveness. In general, it is difficult to determine, within a given individual, whether VNS is affecting brain activity without using expensive imaging techniques. However, acute mild pain procedures, like those used in this study and the studies by Ness et al (14) and Kirchner et al (13), might be used to evaluate whether VNS settings are appropriate for an individual participant by providing clinicians and researchers with a simple, cost-effective method to verify that VNS is indeed affecting the brain.

ACKNOWLEDGEMENTS: This study was funded by an internal grant awarded by the University Research Committee (URC) at the Medical University of South Carolina. The participants enrolled were participants in a clinical trial sponsored and funded by Cyberonics, Inc. The authors would like to acknowledge Minnie Dobbins for her administrative help. 


\section{Borckardt et al}

\section{REFERENCES}

1. Heck C, Helmers SL, DeGiorgio CM. Vagus nerve stimulation therapy, epilepsy, and device parameters: Scientific basis and recommendations for use. Neurology 2002;59(Suppl 4):S31-7.

2. Ben-Menachem E, Manon-Espaillat R, Ristanovic R, et al. Vagus nerve stimulation for treatment of partial seizures: 1 . A controlled study of effect on seizures. First International Vagus Nerve Stimulation Study Group. Epilepsia 1994;35:616-26.

3. Ben-Menachem E, Hamberger A, Hedner T, et al. Effects of vagus nerve stimulation on amino acids and other metabolites in the CSF of patients with partial seizures. Epilepsy Res 1995;20:221-7.

4. Ben-Menachem E. Vagus nerve stimulation, side effects, and longterm safety. J Clin Neurophysiol 2001;18:415-8.

5. Helmers SL, Wheless JW, Frost M, et al. Vagus nerve stimulation therapy in pediatric patients with refractory epilepsy: Retrospective study. J Child Neurol 2001;16:843-8.

6. Labar D, Dean A. Neurostimulation therapy for epilepsy. Curr Neurol Neurosci Rep 2002;2:357-64.

7. Amar AP, Levy ML, McComb JG, Apuzzo ML. Vagus nerve stimulation for control of intractable seizures in childhood. Pediatr Neurosurg 2001;34:218-23.

8. Sackeim HA, Rush AJ, George MS, et al. Vagus nerve stimulation (VNS) for treatment-resistant depression: Efficacy, side effects, and predictors of outcome. Neuropsychopharmacology 2001;25:713-28.

9. Marangell LB, Rush AJ, George MS, et al. Vagus nerve stimulation (VNS) for major depressive episodes: One year outcomes. Biol Psychiatry 2002;51:280-7.

10. Rush AJ, George MS, Sackeim HA, et al. Vagus nerve stimulation (VNS) for treatment-resistant depressions: A multicenter study. Biol Psychiatry 2000;47:276-86.

11. George MS, Nahas Z, Bohning DE, et al. Vagus nerve stimulation therapy: A research update. Neurology 2002;59(Suppl 4):S56-61.

12. Henry TR. Therapeutic mechanisms of vagus nerve stimulation. Neurology 2002;59(Suppl 4):S3-13.

13. Kirchner A, Birklein F, Stefan H, Handwerker HO. Left vagus nerve stimulation suppresses experimentally induced pain. Neurology 2000;55:1167-71.

14. Ness TJ, Fillingim RB, Randich A, Backensto EM, Faught E. Low intensity vagal nerve stimulation lowers human thermal pain thresholds. Pain 2000;86:81-5.
15. Turk DC, Gatchel RJ, eds. Psychological Approaches to Pain Management: A Practitioner's Handbook, 2nd edn. New York: The Guilford Press, 2002.

16. Campbell LC, Clauw DJ, Keefe FJ. Persistent pain and depression: A biopsychosocial perspective. Biol Psychiatry 2003;54:399-409.

17. Ren K, Randich A, Gebhart GF. Spinal serotonergic and kappa opioid receptors mediate facilitation of the tail flick reflex produced by vagal afferent stimulation. Pain 1991;45:321-9.

18. Ren K, Randich A, Gebhart GF. Effects of electrical stimulation of vagal afferents on spinothalamic tract cells in the rat. Pain 1991;44:311-9.

19. Ammons WS, Blair RW, Foreman RD. Vagal afferent inhibition of primate thoracic spinothalamic neurons. J Neurophysiol 1983;50:926-40.

20. Maixner W, Bossut DF, Whitsel EA. Evaluation of vagal afferent modulation of the digastric reflex in cats. Brain Res 1991;560:55-62.

21. Lomarev M, Denslow S, Nahas Z, Chae JH, George MS, Bohning DE. Vagus nerve stimulation (VNS) synchronized BOLD fMRI suggests that VNS in depressed adults has frequency/dose dependent effects. J Psychiatr Res 2002;36:219-27.

22. Henry TR, Bakay RA, Votaw JR, et al. Brain blood flow alterations induced by therapeutic vagus nerve stimulation in partial epilepsy: I. Acute effects at high and low levels of stimulation. Epilepsia 1998;39:983-90.

23. Mu Q, Bohning DE, Nahas Z, et al. Acute vagus nerve stimulation using different pulse widths produces varying brain effects. Biol Psychiatry 2004;55:816-25.

24. Mu Q, Bohning DE, Nahas Z, et al. Acute vagus nerve stimulation using different pulse widths produces varying brain effects. Biol Psychiatry 2004;55:816-25.

25. Banks SM, Kerns RD. Explaining high rates of depression in chronic pain. A diathesis-stress framework. Psychol Bull 1996;119:95-110.

26. Magni G, Marchetti M, Moreschi C, Merskey H, Rigatti-Luchini S. Chronic musculoskeletal pain and depressive symptoms in the National Health and Nutritional Examination I: Epidemiologic follow-up study. Pain 1993;53:163-8. 


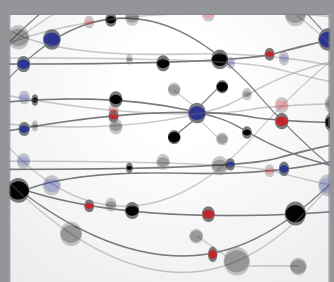

The Scientific World Journal
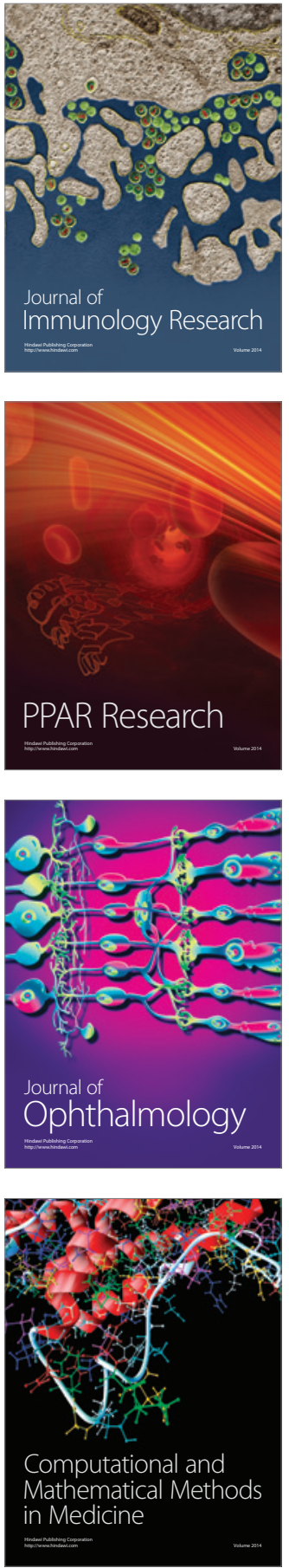

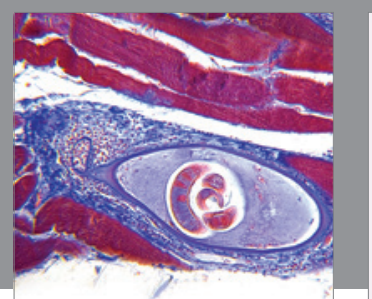

Gastroenterology Research and Practice

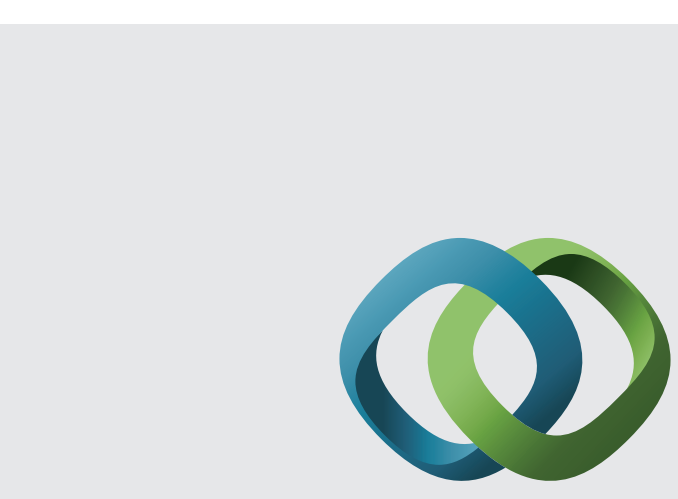

\section{Hindawi}

Submit your manuscripts at

http://www.hindawi.com
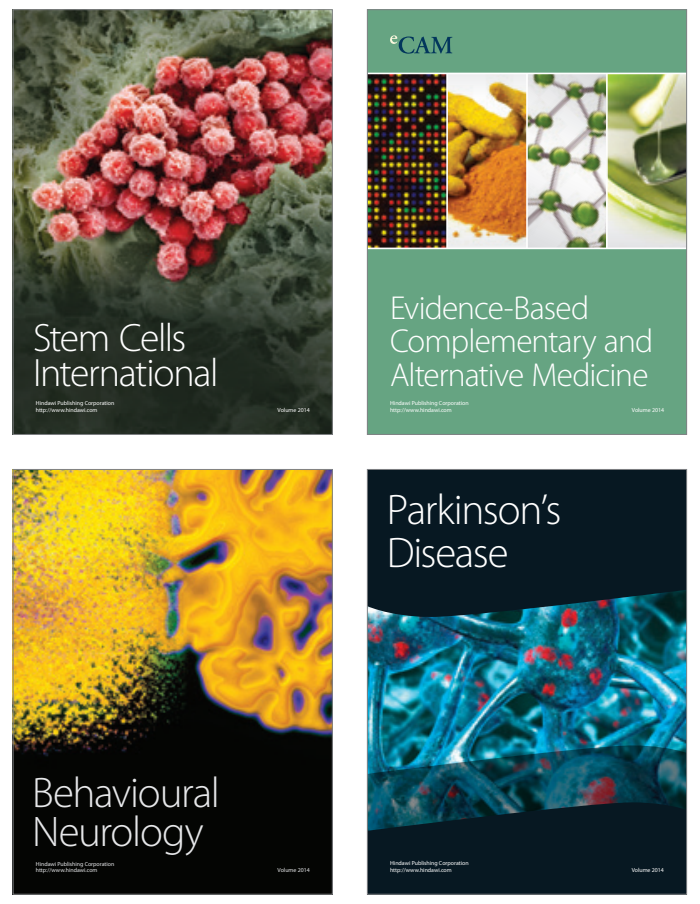
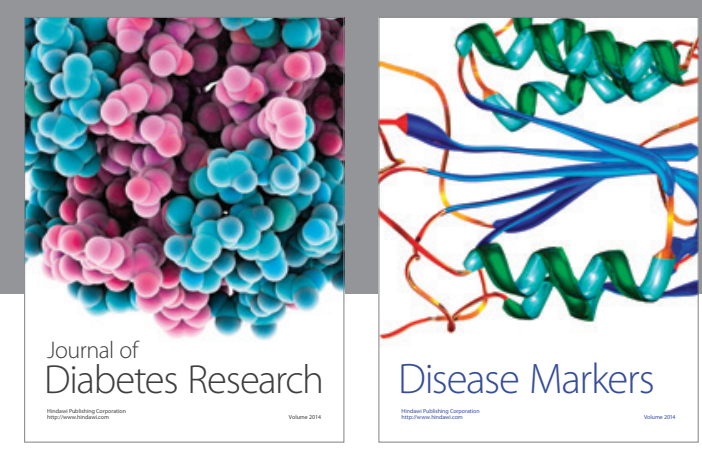

Disease Markers
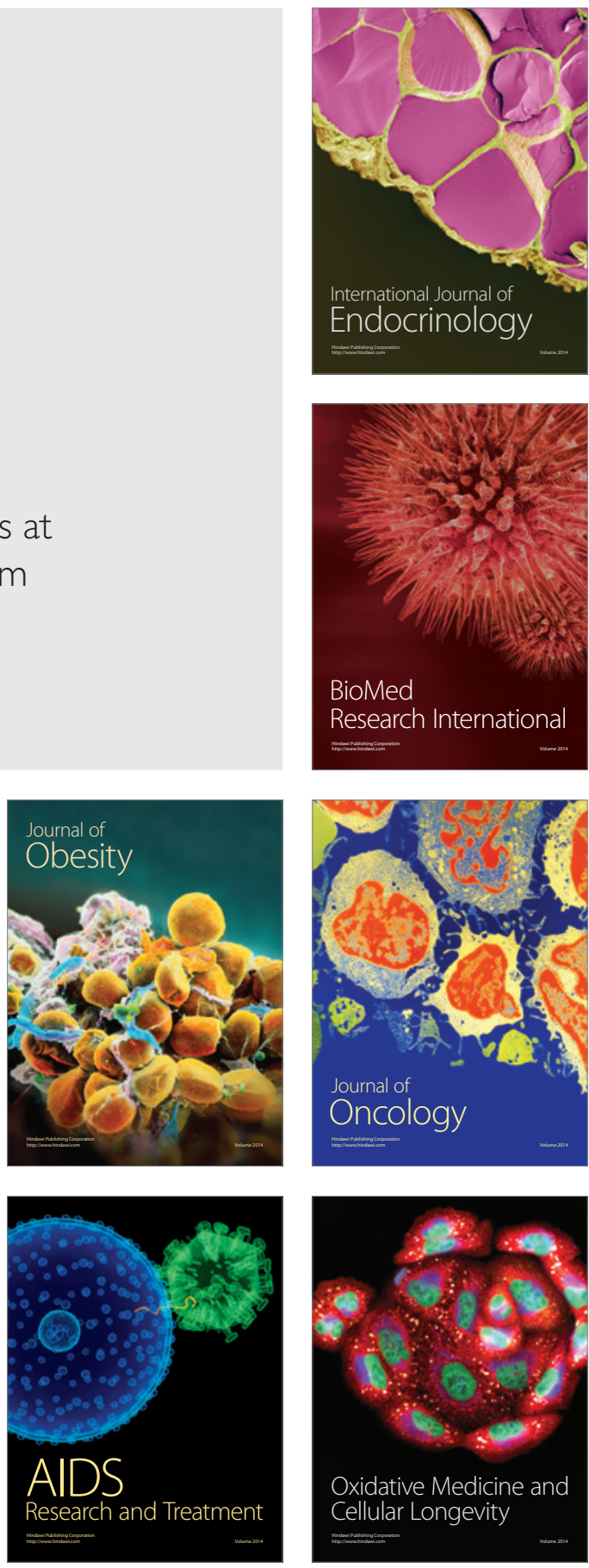